\title{
Design Analysis of the Hydraulic System for Containerized Oil Boom
}

\author{
Muhammad Badrus Zaman ${ }^{1}$, Agoes Santoso ${ }^{2}$, Malik Fahadh ${ }^{3}$ \\ (Received: 01 August 2019 / Revised: 1 June 2020 / Accepted: 21 June 2020)
}

\begin{abstract}
The function of the Oil Boom itself is to limit the oil spill so that it doesn't spread too wide. The hydraulic system is a system that utilizes pressurized liquid fluid as the actuator drive media. The concept of the technical analysis of this system is the design of the winch system using a hydraulic motor which is a driving device as well as a roller of an oil boom that has a length of 2 kilometers and then stored into the drum that has been designed. All components are in a container package that has been designed to place the position and layout. To see the advantages and disadvantages of the system design, technical analysis is carried out. From the results of data processing, it can be calculated for the torque moment of the drum, which is equal to 9,344.416 Nm and weighs $242.697 \mathrm{~kg}$. BLACKBRUIN BBC05 type hydraulic motor has been determined, which has a torque of 10,360-13,305 Nm and a pressure of 350-400 bar. After the total air demand for the oil boom as long as $2 \mathrm{~km}$ is known, which is equal to 552,951 cm3, the next step is to select the right compressor. Selected type TANABE TASK-25110 compressor with a capacity of $1,020 \mathrm{~m} 3 / \mathrm{hour}$. That way, it can be determined the air filling time for the oil boom is 0.542 hours $= \pm 35-40$ minutes.
\end{abstract}

Keywords—container, drum, hydraulic, oil boom, winch

\section{INTRODUCTION}

$\mathrm{O}_{\mathrm{i}}$ 1 and gas are still a source of energy, which is the main choice for human use in various needs in industry, transportation, and households. In addition, the utilization of various oil and gas products is also increasing so that the increase in demand for petroleum throughout the world has resulted in growth and expansion in oil exploration, exploitation, and processing activities in various countries, including Indonesia. However, we are always faced with a dilemma between increasing oil and gas production and the preservation of natural and environmental resources, as well as the impact of the production process so that it cannot be denied that the development of the oil and gas industry is one source of environmental pollutants [1]. activities, starting from the exploration phase, including geological investigation, seismic activities, to drilling for oil and gas sources as well as exploitation, namely oil and gas uptake and downstream business activities, namely processing at refineries, distribution, storage, and commerce has the potential to cause environmental damage [2].

The oil spill at sea is one of the work accidents carried out by companies that produce oil. Many large companies use petroleum as one of their products. With this, the oil spill accident in the sea is very likely. Oil spills at sea can cause pollution that has a very influential ecosystem. The oil spill can be cleaned using several methods, like using an oil boom, using a sponge, etc. [3].

The oil boom is the equipment used to localize or contain oil spills in the sea. The spread of oil boom is the initial action taken when an oil spill occurs. The oil boom localizes and prevents the oil from spreading

TABLE 1.

CONTAINER SIZE

\begin{tabular}{cccc}
\hline & Length (m) & Width (m) & Height (m) \\
\hline $\begin{array}{c}\text { Outer } \\
\text { Size }\end{array}$ & 6.058 & 2.438 & 2.591 \\
Inner Size & 5.919 & 2.340 & 2.380 \\
\hline
\end{tabular}

Environmental pollution due to oil and gas industry business activities can occur from upstream business activities to downstream business activities. In the production process, it starts from upstream business

\footnotetext{
Muhammad Badrus Zaman, Department of Marine Engineering, Institut Teknologi Sepuluh Nopember, Surabaya 60111, Indonesia, Email: druz_zaman@yahoo.com

Agoes Santoso, Department of Marine Engineering, Institut Teknologi Sepuluh Nopember, Surabaya 60111, Indonesia, E-mail: Agoes295@gmail.com

Malik Fahadh, Department of Marine Engineering, Institut Teknologi Sepuluh Nopember, Surabaya 60111, Indonesia, E-mail: kingfahadhmalik@gmail.com
}

contaminating a wider area. With this, the oil boom requires a tugboat for the deployment process at sea and requires a driving device used to pull the oil boom. The driver is used to pull the oil boom from the sea when it's finished using it. The oil boom that has been used certainly has a heavyweight because it has been mixed with seawater, so a tool is needed to attract it [4].

\section{METHOD}

\section{A. Identification of Problem}

In this sub-section, the initial problem formulation is carried out by searching for information related to the problems in the oil boom. Search for initial information 
is obtained from sources through searching from secondary data and performing calculations. After that, the writer can determine the formulation of the problem related to the research objectives. the next stage must repeat at the data collection stage which aims to find data that can meet the output power required.

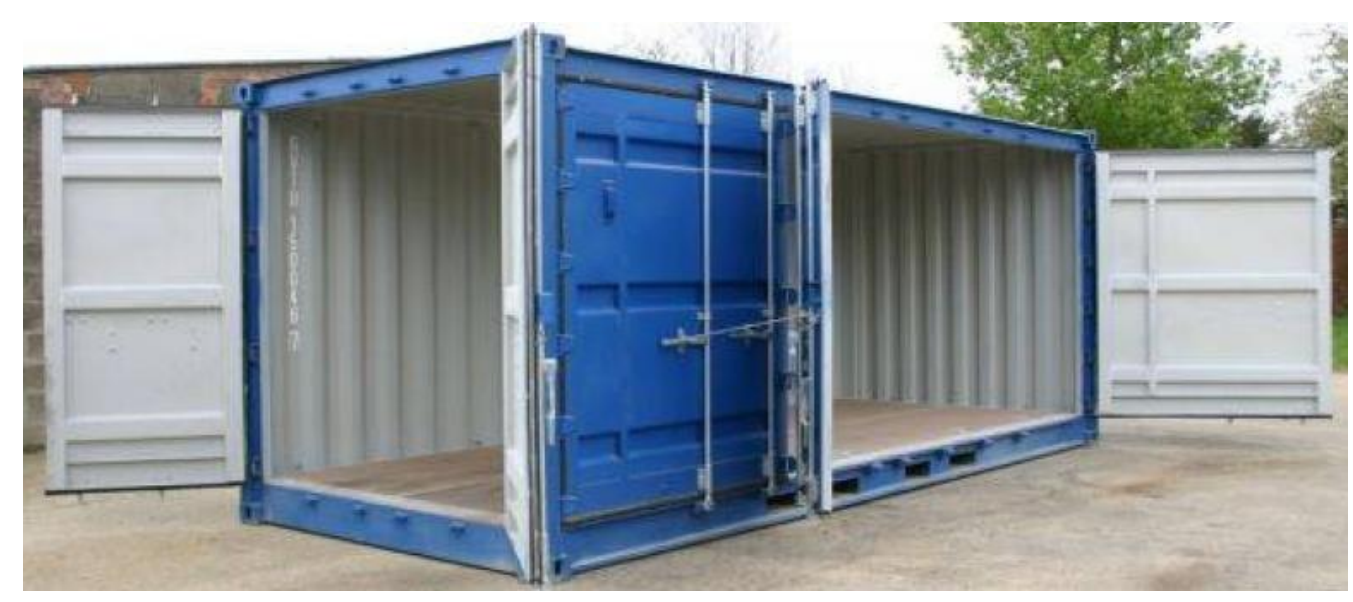

Figure. 1. Openside container 20ft.

\section{B. Study of Literature}

Are conducted with the aim of obtaining concepts and methods related to problem solving and solutions in conducting this research. This study uses literature studies as input to study and understand about matters relating to material or research theories that will be discussed.

\section{Data Collection}

It is a process that will be used and needed in the completion of a paper either from a reference book or various parties and other things that if it can support in terms of analyzing and resolving the problems.

\section{RESULTS AND DISCUSSION}

\section{A. Oil Boom Specification}

To do the next step, an oil boom specification is needed to be used. The selected oil boom specifications are as follows:

$\begin{array}{lllll}\text { Freeboard } & : 12 & \text { Inch } & : 0,304 & \text { Meter } \\ \text { Boom Overall } & : 36 & \text { Inch } & : 0,914 & \text { Meter } \\ \text { Length } & : 50 & \text { Feet } & : 15 & \text { Meter }\end{array}$

\section{B. Drum Calculation and Container Selection}

Drum is a tool that is used to be one of the containers of oil boom that has been stretched by a winch. Drum

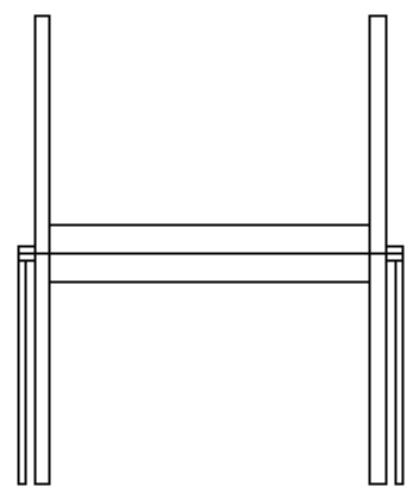

Front View

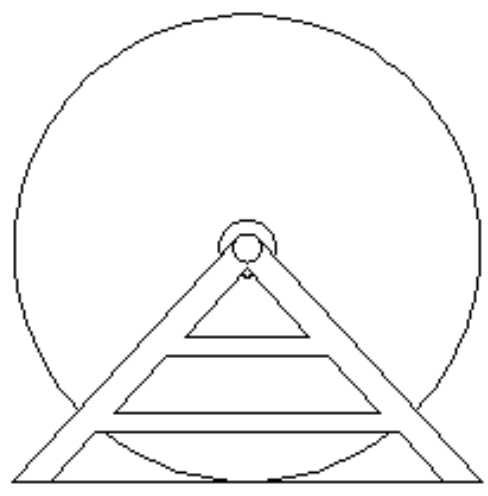

Side View

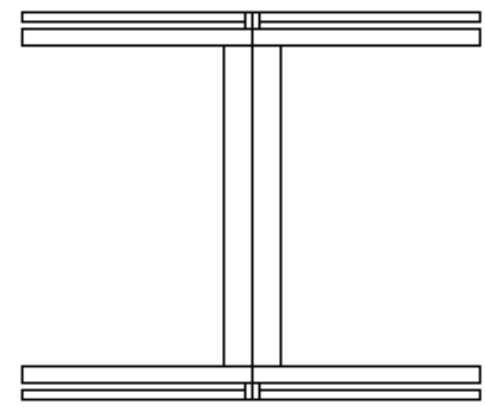

Top View

Figure. 2. Drum design.

\section{Technical Design}

Data modeling is the stage used to design oil boom drives using winches with hydraulic systems in containers as a package of storage systems [5].

\section{E. Analysis of Result}

If the results of the previous design have fulfilled the requirements, then the next stage can be carried out, but if the design results do not meet the requirements, then design is calculated by adjusting the size of the storage space. The drum storage space is using an openside type, 20 feet container [6].

By knowing the size of the container above the drum dimensions can be determined as follows:

Total Oil Boom Weight : 33.5 Ton

Oil Boom Thickness : $8 \quad \mathrm{~mm}$

Oil Boom Width : :9144 mm 
International Journal of Marine Engineering Innovation and Research, Vol. 5(2), Jun. 2020. 53-58 (pISSN: 2541-5972, eISSN: 2548-1479)

$$
\begin{array}{lll}
\text { Oil Boom Lenth } & : 2 & \mathrm{~km} \\
& : 2000 \mathrm{~m}
\end{array}
$$

Amount of Oil Boom: 134 Parts

Using the dimensions of the drum that has been known, it must be calculated the capacity of the oil boom in one drum.

$$
=44,642.72 \quad \mathrm{~kg} \cdot \mathrm{m}^{2}
$$

\section{E. Drum Torque Moment}

In rotational motion, the cause of rotating objects is the moment of force or torque.

$\tau \quad=\mathrm{I} \times \alpha$

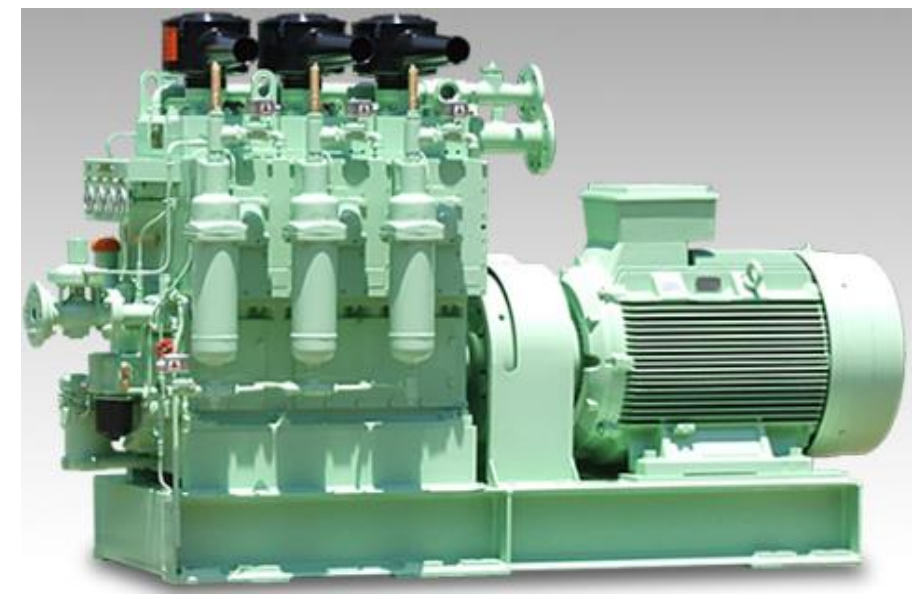

Figure. 3. Compressor.

\section{Drum Capacity $=$ Dedge-Ddrum/Oil Boom Thickness \\ $=2300-70 / 8$ \\ $=278.7$ parts of the oil boom}

With the results of calculating the capacity of the oil boom on the drum above, it was found that one drum was able to roll 279 parts of the oil boom. So in this case, using one drum for 134 parts of the oil boom. Where the capacity of 1 drum is 134 parts in a 20 feet container [7].

\section{Drum Weight}

With the data already known above then:

$\begin{array}{lll}\text { Drum Height } & : 1700 & \mathrm{~mm} \\ \text { Ddrum } & : 70 & \mathrm{~mm} \\ \text { Dinside } & : 27 & \mathrm{~mm} \\ \text { Dedge } & : 2300 & \mathrm{~mm} \\ \text { Dedge thickness } & : 20 & \mathrm{~mm}\end{array}$

$$
\begin{aligned}
\text { Overall weight } & =\text { Dedge }+ \text { Ddrum } \\
& =225.069+17.628 \\
& =242.697
\end{aligned}
$$

\section{Moment of Inertia of The Drum}

Moment of Inertia is defined as the inertia of an object

$$
\begin{aligned}
& =\text { Moment of Inertia x Angular Acceleration } \\
& =44,624.72 \times 0.2094 \\
& =9,344.416 \quad \mathrm{Nm}
\end{aligned}
$$

\section{F. Selection of Hydraulic Motor}

The choice of a hydraulic motor is one of the most important steps to be taken. With the power or torque force selected on the hydraulic motor must exceed or sufficient torque that is owned by the drum. If this is not achieved, the hydraulic motor cannot rotate the existing drum [9].

With the torque data found, hydraulic motors will be used. The required torque is $9,330.376 \mathrm{Nm}$, to choose a hydraulic motor that has a torque of $500 \mathrm{Nm}$ or more it must be calculated the safety factor with $(15 \% \mathrm{x}$ torque needed). Then the selected hydraulic motor must have a minimum torque of $10,729.932 \mathrm{Nm}$. Therefore, the BLACKBRUIN BBC05 type hydraulic motor was chosen, which has a torque of 10,360-13,305 Nm and a pressure of 350-400 bar.

\section{G. Compressor Selection}

It selected type TANABE TASK-25110 compressor TABLE 2.

\begin{tabular}{ccccc}
\multicolumn{5}{c}{ TECHNICAL SPECIFICATION OF HYDRAULIC MOTOR } \\
\hline $\begin{array}{c}\text { Pressure } \\
(\mathrm{Bar})\end{array}$ & Torque $(\mathrm{Nm})$ & $\begin{array}{c}\text { Displacement } \\
\left(\mathrm{cm}^{3}\right)\end{array}$ & $\begin{array}{c}\text { Rotational } \\
\text { Speed }(\mathrm{rpm})\end{array}$ \\
\hline Minimum & 350 & 10,360 & 1,572 & 142 \\
Maximum & 400 & 13,305 & 2,271 & 205 \\
\hline
\end{tabular}

to rotate on its axis, or it can be said a measure of the difficulty to make an object rotate or move in a circle. The moment of inertia depends on the shape of the object and the position of the axis of the rotating object [8].

$$
\begin{aligned}
\mathrm{I} & =\mathrm{m} \cdot \mathrm{r}^{2} \\
& =\text { Mass } \mathrm{x} \text { Drum Radius } \\
& =(\text { Oil Boom Weight }+ \text { Drum Weight }) \times \text { Drum Radius } \\
& =(33,500+247.7) \times 1.15^{2}
\end{aligned}
$$

with a capacity of $1020 \mathrm{~m} 3$ / hour. That way, it can be determined that the air filling time for the oil boom is $1020 / 553=0.542$ hours $= \pm 35-40$ minutes. 


\section{H. Layout Components Inside The Container}

The layout of the components inside the container needs to be considered because it affects the flexibility of the operation. With the layout arranged can affect the strength of the foundation structure in the container [10].
3. Hazard Identification \& Potential Accidents Identify all possible hazards, including in each work procedure. Identify all hazards caused by the surrounding environment and work-related. Hazard identification includes assessing the severity level (severity/impact),

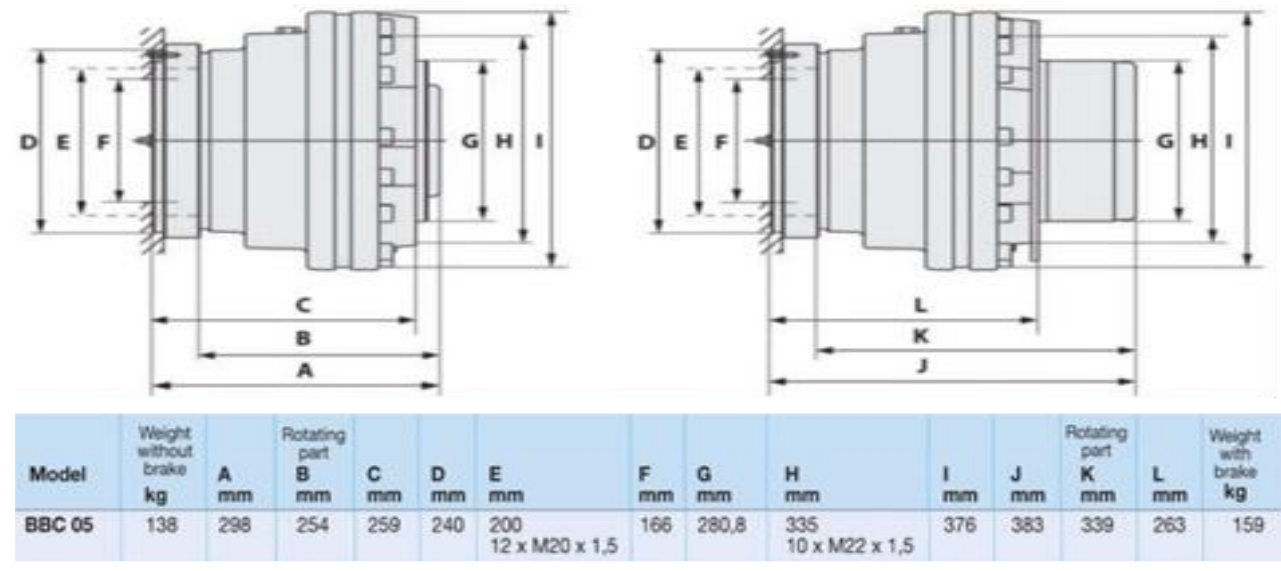

Figure. 4. Dimension of Hydraulic Motor.

\section{Winch Planning}

For the purpose of loading and unloading the existing oil boom, a calculation plan for the winch is needed on the ship

\section{J. Job Safety Analysis}

Below are the steps for developing a JSA (Job Safety Analysis), as follows: likelihood (possibility), and determining the risk control of the hazards that arise.

The final step in the JSA is to develop safe work procedures to prevent incidents or potential accidents. The main point of Job Safety Analysis is to prevent accidents by anticipating, eliminating, and controlling existing hazards.

TABLE 3.

JOB SAFETY ANALYSIS

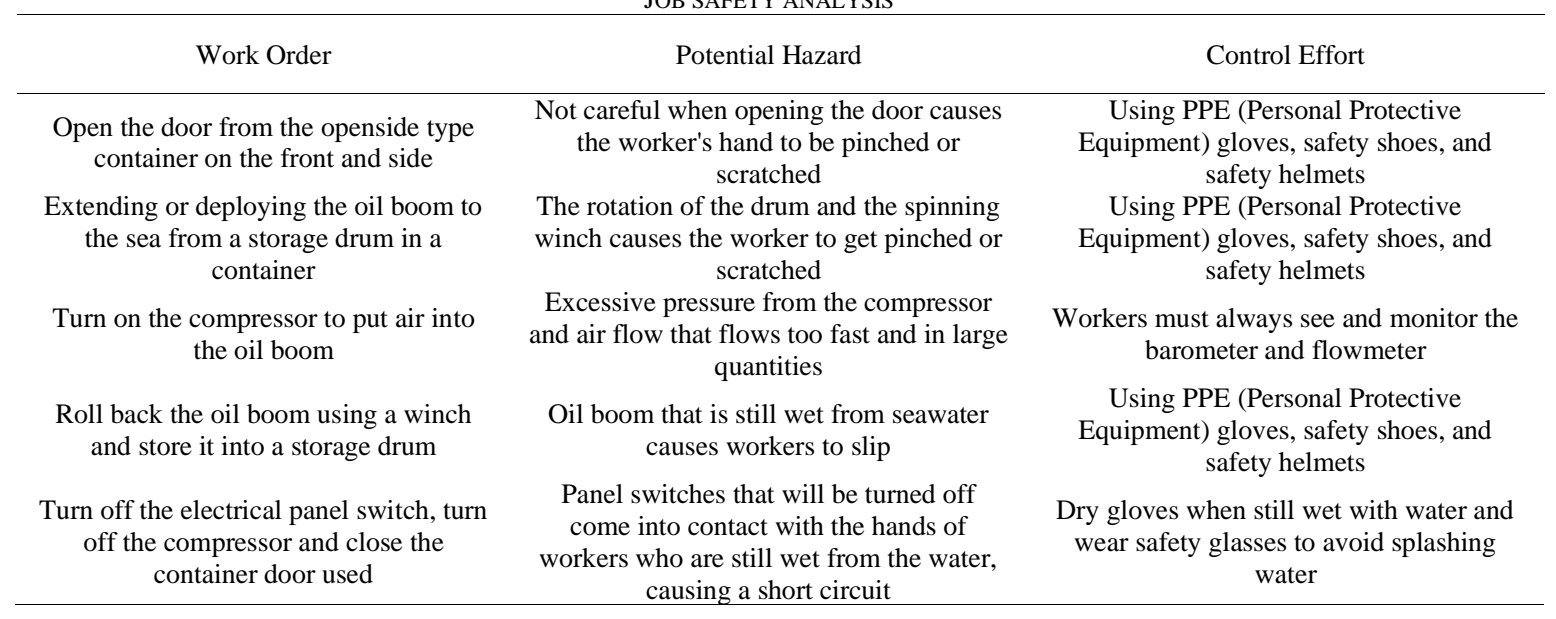

1. Choosing a Job

Jobs with a high level of accident history, have top priority, and must be immediately analyzed. In choosing the work to be analyzed, a supervisor must consider several factors.

2. Sharing Work

Choose workers who are experienced, have the ability, and are cooperative, so they are able to share ideas and explain the goals and benefits of the JSA to workers.

\section{CONCLUSION}

After going through various processes of guidance and explanation of the process concluded based on the results it can be concluded that the design of hydraulic winch system and storage drum for $2 \mathrm{~km}$ oil boom in the $20 \mathrm{ft}$ open side container is as follows: 
1. In the technical analysis of hydraulic winch system design and storage drum for a $2 \mathrm{~km}$ oil boom in a $20 \mathrm{ft}$ open container, it is known that the total weight of the oil boom per section is $250 \mathrm{~kg} /$ part. For a $2 \mathrm{~km}$ oil boom, there are 134 parts of the oil boom with a total overall weight torque of $500 \mathrm{Nm}$ or more, it must be calculated with the safety factor ( $15 \% \mathrm{x}$ torque needed). Then the selected hydraulic motor must have a minimum torque of $10,729,932 \mathrm{Nm}$. Therefore, the BLACKBRUIN BBC05 type hydraulic motor was chosen, which has a torque of 10.360-

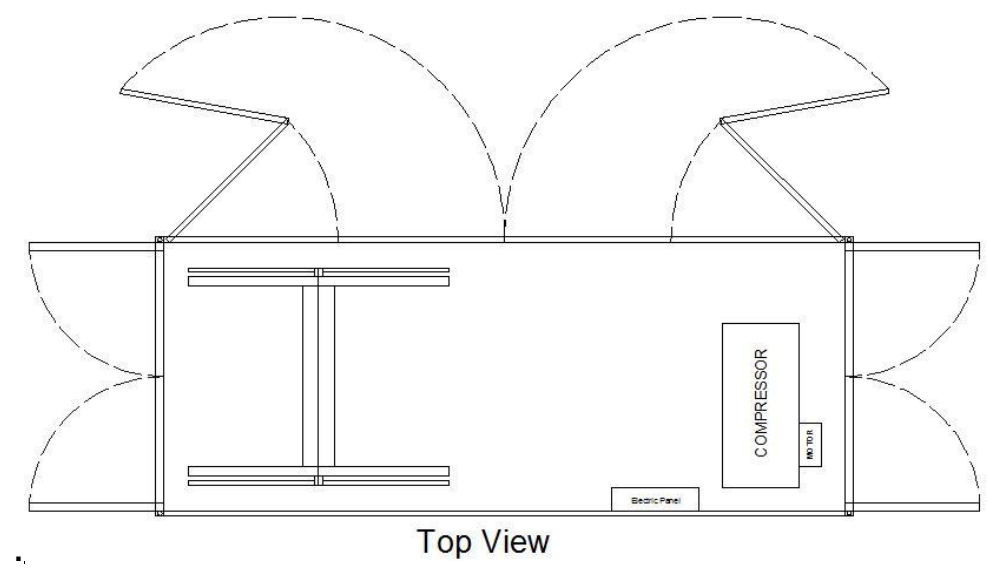

Figure. 5. Top view of layout.

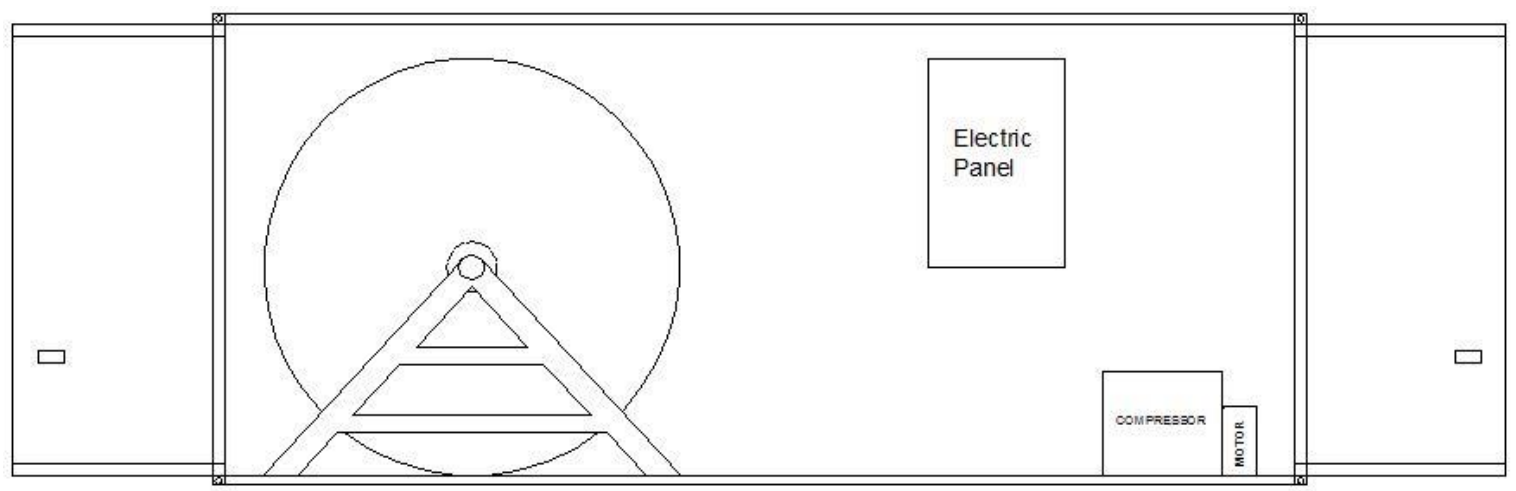

\section{Side View}

Figure. 6. Side view of layout.

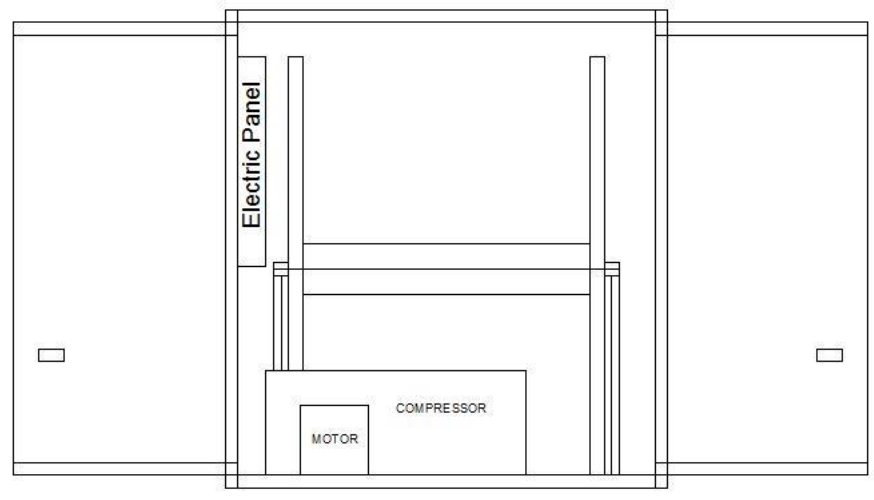

Front View

Figure. 7. Front view of layout.

of 33.5 tons. It is also known that the air volume needed by the oil boom is $552,951 \mathrm{~cm} 3$. With the torque data that has been determined, the hydraulic motor that will be used can be determined. The required torque is 9,330,376 Nm. To choose a hydraulic motor that has a
13.305 Nm and a pressure of 350-400 bar. After the total air demand for oil boom as long as $2 \mathrm{~km}$ 
It is known, which is equal to $552,951 \mathrm{~cm} 3$, the next step is to select the right compressorselected type TANABE TASK-25110 compressor with a capacity of 1,020 m3 / hour. That way, it can be determined the air filling time for the oil boom for 0.542 hours $= \pm 35-40$ minutes.

2. Storage drums are also specially made and different according to the oil boom needs by taking into account aspects such as oil boom length and material used. With the calculation of the capacity of the oil boom on the storage drum, it is known that it can roll as many as 279 parts of the oil boom, so in this design, it is enough to use one storage drum for 134 parts. The overall weight of the storage drum is known to weigh $242,697 \mathrm{~kg}$, and the material used for the storage drum is aluminum.

3. The container as a storage place is chosen by the type of openside container with a size of $20 \mathrm{ft}$ for operating flexibility, and for the position of each component laying layouts have been carried out within the container with regard to vibrations when operated and the structure of the foundation. The layout or layout has also been made to pay attention to the operating flexibility and analysis of work safety.

4. The main points of Job Safety Analysis are to prevent accidents by anticipating, eliminating, and controlling the hazards that exist.

The technical analysis of the design differs from pneumatic systems because the hydraulic system cannot be combined with a compressor for its drive system (hydraulic motor), so the compressor is only used to fill the air in the oil boom.

\section{REFERENCES}

[1] D. S. Etkin, "Modeling oil spill response and damage costs." Freshwater spills symposium 2004. The United States Environmental Protection Agency, Washington, D.C., USA. 2004.

[2] M. F. Fingas, "The basics of oil spill cleanup." 3rd Edition. Taylor and Francis Group, Boca Raton, Florida, USA. 2012.

[3] P. Herrington, G. Ball, and K. O'Halloran. "Aquatic ecotoxicity of cutback bitumen." Land Transport New Zealand, Wellington, New Zealand. 2006

[4] Marine Pollution 73/78

[5] American Petroleum Institute. "Oil spill response: options for minimizing adverse ecological impacts." American Petroleum Institute, Washington, D.C., USA. 1985.

[6] British Columbia Ministry of Environment (BC-MOE). "British Columbia marine oil spill response plan." Provincial document. British Columbia Ministry of Environment, Victoria, British Columbia, Canada. 2013.

[7] International Energy Agency (IEA). "World Energy Outlook 2010." International Energy Agency, Paris, France. 2010.

[8] T. Nyman, "Evaluation of methods to estimate the consequence costs of an oil spill." SKEMA Seventh Framework Programme, Athens, Greece. 2009.

[9] A. Nelson-Smith, "Oil pollution and marine ecology." Plenum, New York, USA. 1973

[10] Port Metro Vancouver. "Tanker traffic: oil tanker movement." Port Metro Vancouver, British Columbia, Canada. 2013.

[11] M. Boulton, "Financial vulnerability assessment: who would pay for oil tanker spills associated with the Northern Gateway pipeline?" University of Victoria, Environmental Law Centre, Victoria, British Columbia, Canada. 2010.

[12] British Columbia Government. "Requirements for British Columbia to consider support for heavy oil pipelines." Provincial document. British Columbia Government, Victoria, British Columbia, Canada. 2012.

[13] Conversations for Responsible Economic Development. "Assessing the risks of Kinder Morgan's proposed new Trans Mountain pipeline." Conversations for Responsible Economic Development, Vancouver, British Columbia, Canada. 2013.

[14] E. J. Danielson, "A study of the economic impact of the Deepwater Horizon oil spill - Part 3: public perception." Greater New Orleans, Inc., New Orleans, Louisiana, USA. 2011.

[15] David Suzuki Foundation. "Oil spill scenarios." Video. David Suzuki Foundation, Vancouver, British Columbia, Canada. 2013. 